\title{
Retinal Vein Occlusion Induced by a MEK Inhibitor - Impact of Oxidative Stress on the Blood-Retinal Barrier
}

\author{
Amy H. Yang and Wenhu Huang \\ Drug Safety Research \& Development, \\ Pfizer Inc., La Jolla Laboratories, \\ USA
}

\section{Introduction}

The retina is a highly specialized sensory organ that transduces light energy into neural signal. It also has high energy requirement and an extensive vascular network. Reactive oxygen species (ROS) generated via light exposure, normal energy production, phagocytosis of spent photoreceptor membranes by retinal pigment epithelium (RPE) cells, and circulating toxins render retina at an increased risk for oxidative stress (Hardy et al., 2005; Siu et al., 2008). To cope with the high oxidant load, the retina is equipped with various antioxidant defense mechanisms, such as the expression of glutathione peroxidase and superoxide dismutase, the production of glutathione by Müller cells, high levels of vitamins $\mathrm{C}$ and $\mathrm{E}$, and the presence of free radical scavenger melanin in RPE cells (Siu et al., 2008). However, when the redox balance is disrupted, retinal pathologies could result, and one of the consequences is impairment of the blood retinal barrier (BRB). Indeed, several retinal diseases have been shown or postulated to be linked to a state of oxidative stress and resulting BRB dysfunction.

Previously, we investigated the molecular mechanisms towards the development of retinal vein occlusion (RVO) in cancer patients treated with a mitogen-activated protein kinase kinase (MEK) inhibitor, PD0325901 (LoRusso et al., 2010). Through gene expression profiling analysis, we identified several mechanisms relevant to the development of RVO, including oxidative stress response, acute phase and inflammatory response, blood-retinal barrier (BRB) breakdown, leukostasis, and coagulation cascade (Huang et al., 2009).

This chapter aims to provide an overview of BRB structures and functions, the role of oxidative stress in BRB disruption and development of retinal pathologies, a detailed overview of RVO, and finally, a description of proposed mechanisms of PD0325901-induced RVO, highlighting several important cellular and molecular processes relevant to this pathology.

\section{Blood-retinal barrier}

The BRB has an endothelial and an epithelial component, namely the tight junctions between the endothelial cells of the inner retinal vessels, and those between cells of the RPE; 
these cell types comprise integral components of the inner and outer BRB, respectively (Siu et al., 2008; Fig. 1A). The BRB regulates the transport of fluid and molecules between the retinal tissue and vasculature, hence playing an important role in maintaining the homeostatsis of the retinal microenvironment (Kaur et al., 2008; Siu et al., 2008).

\subsection{Inner blood-retinal barrier}

The inner BRB is composed of endothelial cells, astrocytes, Müller cells, and pericytes (Fig. 1A). Tight junctions between capillary endothelial cells form the basis of the inner BRB (Fig. 1B). Astrocytes, Müller cells and pericytes, all closely associated with the endothelial cells of the inner BRB, contribute to proper BRB functions.

The endothelial cells of inner retinal capillaries are not fenestrated, contributing to their low permeability. Solutes traverse the retinal endothelium via both the transcellular and paracellular pathways: the former involves vesicle-mediated transport of macromolecules, and the latter, passage through minute intercellular space safeguarded by junctional proteins (Vandenbroucke et al., 2008; Fig. 1B). Tight junctions consist of occludins, claudins, and junctional adhesion molecules (JAMs), all of which form complexes between adjacent endothelial cells. Zonula occludens (ZO) proteins link occludins and claudins to the endothelial actin cytoskeleton via cingulin. In addition to tight junctions, adherens junctions (AJ) also contribute to the endothelial barrier, where vascular endothelial (VE) cadherins on adjacent endothelial cells form a homophilic complex (Garrido-Urbani et al., 2008; Vandenbroucke et al., 2008). The C-terminal domain of VE-cadherin binds $\beta$-catenins and $\alpha$ catenins, linking the AJs to the actin cytoskeleton. Several lines of evidence show that the regulation of actin cytoskeletal dynamics is central to the proper functioning of the endothelial barrier (Houle and Huot, 2006; Houle et al., 2003; Huot et al., 1998; Lum and Roebuck, 2001). It has also been reported that retinal endothelial cells are more susceptible to oxidative damage, leading to increased permeability, than endothelial cells at other sites. Indeed, ROS are also known to induce the expression of vascular endothelial growth factor (VEGF), a well-known endothelial mitogen and permeability factor, which contributes to the breakdown of BRB in experimental diabetes models (Chua et al., 1998; El-Remessy et al., 2003).

Pericytes line the outer surface of endothelial cells (Fig. 1A) and are contractile in nature, expressing actin, myosin, and tropomyosin (Kaur et al., 2008). They contract in response to signals such as hypoxia, endothelin-1, and angiontensin II, and relax on exposure to carbon dioxide, nitric oxide and adenosine. Therefore, pericytes regulate the vascular tone and blood flow. Under normoxia, they maintain the integrity of the inner BRB by inducing mRNA and protein expression of occludin and ZO-1, and by partially reversing the occludin decrease under hypoxia. Loss of pericytes and disruption of inner BRB are early events in diabetes.

Müller cells are the principal glial cells of the retina, and a functional link between neurons and vessels (Reichenbach et al., 2007). They span the inner and outer limiting membranes of the retina, with their foot processes in close contact with the retinal endothelial cells (Fig. 1A). Under physiological conditions, Müller cells contribute to the integrity of the BRB; however, when exposed to cellular stress they impair the barrier function. Under normoxia, Müller cells secrete pigment epithelium-derived factor (PEDF), 


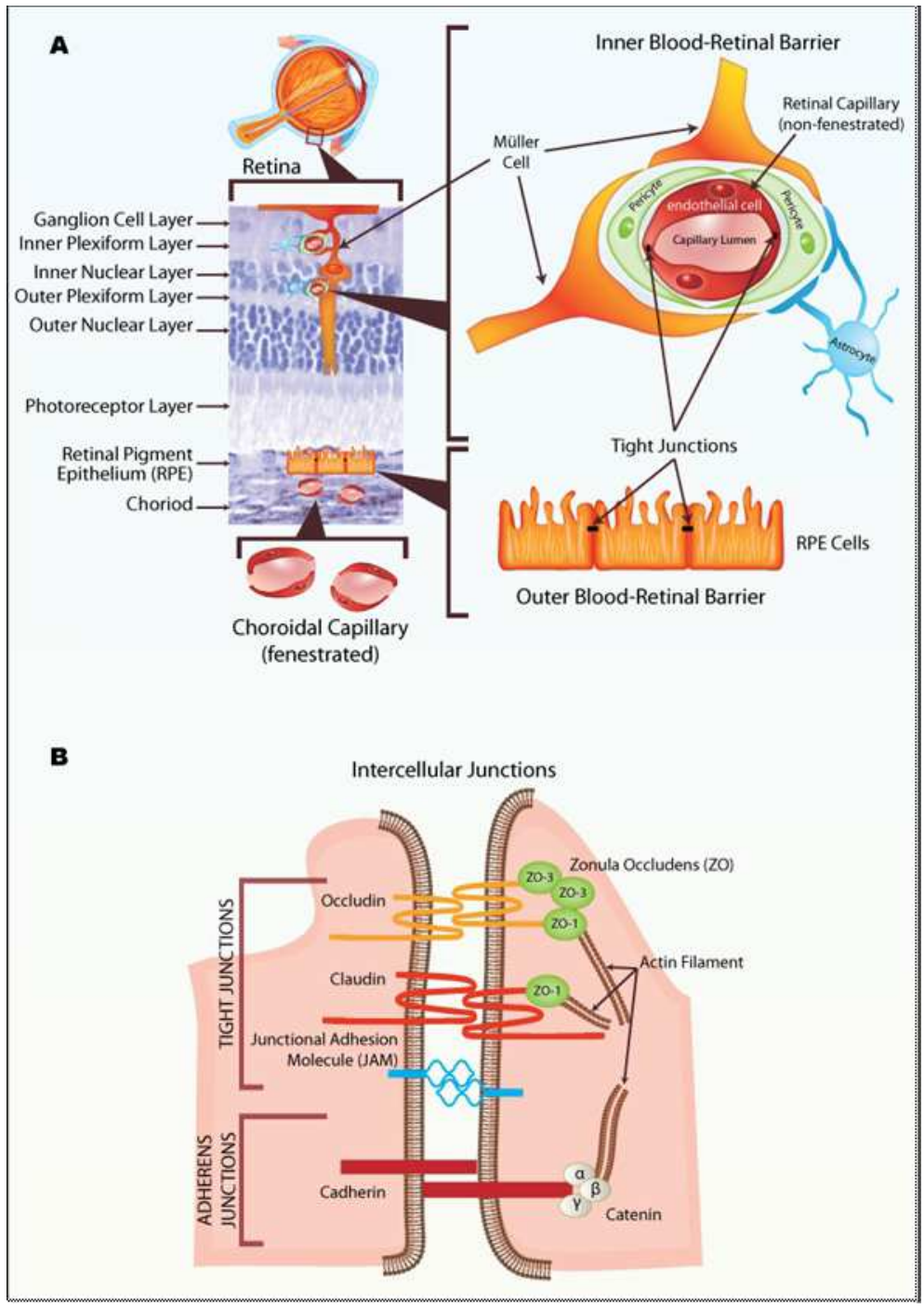

Fig. 1. The blood-retinal barrier (A) The retina is a multi-layered tissue in the posterior segment of the eye, and is shown by the H\&E stained micrograph on the left. The cell types comprising the inner BRB (endothelial cells, pericytes, astrocytes, and Müller cells) and outer BRB (retinal pigment epithelial cells) are overlaid on the retinal micrograph, and are magnified on the right. Tight junctions between retinal capillary endothelial cells and retinal pigment epithelial cells form the basis of the inner and outer BRB, respectively. The endothelial cells of inner retinal capillaries are not fenestrated, whereas those of the choroidal capillaries are (depicted below the retinal micrograph). (B) Protein components of the intercellular junctions. Sources: Kaur et al., 2008; Niessen, 2007;

http://www.landesbioscience.com/curie/images/chapters/Hosoya1.jpg 
which downregulates VEGF expression and decreases vascular permeability (Yafai et al., 2007). Under hypoxia (Kaur et al., 2008) and oxidative stress (Yoshida et al., 2009), PEDF expression is decreased in Müller cells, thus favoring the secretion of VEGF and breakdown of the inner BRB. In addition, Müller cells are a source of matrix metalloproteinases, which proteolytically degrade the tight junction protein occludin, impairing the barrier function of retinal endothelial cells under cellular stress conditions. Müller cells also play a vital role in maintaining the retinal fluid balance (Reichenbach et al., 2007). Under physiological conditions, Müller cells carry out transcellular water transport from the retinal interstitial space into the blood, thus preventing excess fluid buildup within the retina. The transcellular water transport is osmotically coupled to the transport of potassium ions. When exposed to oxidative stress and inflammation, Müller cells have been shown to contribute to retinal edema through a disturbed intracellular fluid transport. Finally, Müller cells also respond to oxidative stress by increasing their production of the antioxidant glutathione (Siu et al., 2008).

Similar to pericytes and Müller cells, astrocytes are closely associated with the retinal vessels (Fig. 1A). They help maintain the BRB integrity by increasing the expression of the tight junction protein ZO-1 and modifying endothelial morphology (Kaur et al., 2008). Dysfunction of astrocytes has been linked to inner BRB breakdown and vasogenic edema.

\subsection{Outer blood-retinal barrier}

The outer BRB consists of tight junctions between RPE cells (Fig. 1A). The RPE is a monolayer of cells between the neuroretina and the choroid, and regulates access of blood components to the retina. Similar to the endothelium, movement across RPE is both transcellular and paracellular. The RPE cells exhibit a polarized morphology, with apical microvilli in contact with photoreceptor outer segments, and basal infoldings adjacent to the Bruch's membrane that separates the retina from choroidal capillaries called choriocapillaris (Kaur et al., 2008). Unlike the capillaries of the inner retina, the choroidal capillaries are fenestrated (Fig. 1A) and therefore do not contribute to the outer BRB (Kaur et al., 2008; Siu et al., 2008). Na+,K+-ATPase and aquaporin 1 (AQP1) expressed on the apical surface regulate movement of sodium, potassium, and water molecules across the RPE. Tight junctions, located at the apical side of the lateral membrane of the RPE cells, restrict paracellular movement between neighboring RPE cells. In addition to its function to regulate molecular transport integral to the outer $\mathrm{BRB}, \mathrm{RPE}$ is responsible for phagocytizing photoreceptor outer segment membranes, which are digested by an extensive lysosome system, whose waste products are removed by the adjacent choriocapillaris (Burke, 2008; Siu et al., 2008). In pigmented animals, RPE cells also express melanin, a free radical scavenger that is also capable of absorbing stray light, and is thought to contribute to the retinal antioxidant mechanisms (Siu et al., 2008).

\section{Oxidative stress, BRB dysfunction and ocular diseases}

\subsection{Sources of ROS in the Retina}

In addition to the mitochondria, cellular sources of ROS in retina include endothelial cell xanthine oxidase, $\mathrm{NAD}(\mathrm{P}) \mathrm{H}$ oxidase, cyclooxygenase (COX), nitric oxide synthase (NOS), 
and lipoxygenase pathways (Frey and Antonetti, 2011; Hardy et al., 2005; Kunsch and Medford, 1999). ROS can also act as intracellular second messengers and activate various signaling transduction pathways.

\subsection{Ocular pathologies associated with oxidative stress and BRB dysfunction}

\subsubsection{Diabetic retinopathy}

Diabetic retinopathy is a significant cause of blindness. Tissue hypoxia and hyperglycemia are generally regarded as contributors to diabetic retinopathy, but how these lead to the disease state is unclear. Current hypotheses, which are not mutually exclusive, for pathogenic mechanisms leading to diabetic retinopathy include oxidative stress, hemodynamic changes, inflammation and the activation of microglia, and increased leukocyte adhesion to the endothelial cells and entrapment (leukostasis) (Chibber et al., 2007). Many of these processes in fact have an association with excessive production of ROS (Yang et al., 2010b). For instance, growing evidence supports an important role for leukostasis in the development of diabetic retinopathy, with downstream consequences including capillary occlusion and localized production of ROS, resulting in endothelial cell damage, BRB breakdown, and increased vascular permeability (Chibber et al., 2007). Inflammatory cytokines interact with cell surface receptors in various cell types to activate signaling pathways that mediate responses of cell adhesion, permeability and apoptosis; they also increase the production of ROS by mitochondria (Busik et al., 2008; Sprague and Khalil, 2009). There are several models that recapitulate various aspects of diabetic retinopathy, including streptozotocin-induced diabetes and ischemia-reperfusion injury.

\subsubsection{Retinopathy of prematurity}

Retinopathy of prematurity (ROP) is a vasoproliferative disease that often develops when premature infants are given supplemental oxygen, and is a leading cause of blindness in children (Hardy et al., 2005; Uno et al., 2010). The developing eye is at an increased risk for oxidative injury from hyperoxia, as the retinal vasculature in premature infants lacks fullydeveloped mechanisms to auto-regulate oxygen tension (Hardy et al., 2005). ROP develops in two phases (Hardy et al., 2005). Hyperoxia in the retina leads to cessation of vascular development, resulting in endothelial cell death, vaso-obliteration and consequently, ischemia. To re-establish retinal perfusion, the retina mounts an exaggerated intravitreal preretinal neovascularization, which may ultimately result in retinal detachment and vision loss. Many features of ROP are recapitulated in oxygen induced retinopathy (OIR) (Brafman et al., 2004; Gu et al., 2002; Uno et al., 2010), in which neonatal animals are exposed to hyperoxia, leading to the generation of ROS, which have been postulated to be causal for vaso-obliteration, death of endothelial cells, and consequently, impairment of the BRB.

\subsubsection{Age-related macular degeneration}

One of the major causes of blindness in the elderly population, age-related macular degeneration (AMD) is characterized by regional degeneration of photoreceptors and the RPE, lipofuscin accumulation in RPE cells, chronic inflammation, and drusen formation. Chronic oxidative stress has also been suggested to be an important factor to the 
pathogenesis of AMD. As alluded to earlier, RPE may be at a high risk for oxidative stress due to its location and function. The RPE is in an oxygen-rich environment adjacent to the choriocapillaris, is continuously exposed to light, sometimes at phototoxic wavelengths, and is responsible for the renewal of photoreceptor outer segments via phagocytosis (Burke, 2008). The high content of polyunsaturated fatty acids of these membrane segments make them susceptible to lipid peroxidation and subsequent free radical formation. Experimental evidence supporting a role of oxidative stress in AMD showed that supplementation of antioxidants in AMD patients has a protective effect, and that cigarette smoking, known to be a source of exogenous free radicals, is a risk factor for AMD (Burke, 2008). Given the central role RPE plays in AMD pathogenesis, a commonly used experimental model to study the link between oxidative stress and AMD involves the use of cultured human RPE (ARPE-19) cells. Common endpoints include cell survival, morphology, activation of signaling cascades, and cytokine production (Chan et al., 2008; Dong et al., 2011; Glotin et al., 2006; Jiang et al., 2009; Klettner and Roider, 2009; Qin et al., 2006; Tsao et al., 2006; Wang et al., 1998; Wu et al., 2010).

\section{Retinal vein occlusion}

Retinal vein occlusion is a vascular disorder of the retina that occurs when one or more of the retinal veins are blocked and the circulation of retinal blood becomes obstructed. This ocular pathology can be a primary lesion or secondary to other retinal diseases. With the blockage, poor venous drainage and increased retinal capillary pressure and permeability ultimately lead to retinal ischemia and edema. Retinal ischemia could lead to the generation of ROS, impacting the integrity of the BRB. Diabetic retinopathy and RVO are the two most common causes of inner BRB breakdown. Among complications found in the clinical examination are hemorrhages, edema, ischemia, neovascularization of the retina as well as increased intraocular pressure. Depending on the location and severity, loss of visual acuity can range from very mild to severe. While some patients with RVO may not have any symptoms, some patients may complain of blurred vision or visual field defects. In severe cases, RVO can lead to vision loss in the affected eye. The most common cause of decreased vision is macular degeneration secondary to RVO, which occurs when leakage within macula leads to macular edema and ischemia. Neovascularization and neovascular glaucoma are the other vision-threatening complications that are devastating for patients with RVO and that should be promptly diagnosed and treated. Vein occlusion is commonly diagnosed by examining the fundus with ophthalmoscope for characteristic morphological changes such as venous tortuosity, cotton-wool spots, dot and flame hemorrhage, and edematous optic nerves, and by fluorescein angiography for vasculature blood flow obstruction, leakage in the retina, retinal ischemia, aneurysm, neovascularization, and macular edema. Sometimes optical coherence tomography (OCT) is used to measure retinal thickness for the determination of the presence of macular edema. Central and peripheral visual disturbance should be evaluated by functional tests in the physical examination.

\subsection{Classification of RVO}

Retinal vein occlusion is primarily classified into central retinal vein occlusion (CRVO) and branch retinal vein occlusion (BRVO) based on the location of obstruction. In CRVO, the occlusion of the central retinal vein can slow or stop blood from leaving the retina and 
therefore most of the retina is affected. In BRVO, when macular venules are occluded, a vision decrease can occur depending on the amount of ischemia and edema. When one of the vein's two trunks is blocked and half of the retina is affected, it is called hemi-central retinal vein occlusion (HRVO). According to several RVO epidemiology studies, the prevalence of both CRVO and BRVO increases significantly with age, more in middle-aged and elderly populations and uncommon in young adults under the age of 40 . Most patients with CRVO are male and over 65 years of age, but there seems to be no gender difference for BRVO. Most CRVO cases are unilateral and painless and only 6-14\% of cases are found to be bilateral (Cheung et al., 2008; Klein et al., 2008; Lim et al., 2008; Marcucci et al., 2011; Xu et al., 2007). A recent combined world-wide data pool, containing 68,751 individuals with ages ranging from 30 to 101 years, suggested that approximately 16 million people are affected by RVO with 5.2 per 1000 for any RVO, 4.42 per 1000 for BRVO and 0.8 per 1000 for CRVO. The incidence of CRVO was lower than that of BRVO in all ethnic populations (Rogers et al., 2010). However, CRVO is the most clinically relevant RVO as it is associated with severe vision loss, especially for the ischemic (non-perfused or hemorrhagic retinopathy) RVO. Among the complications of RVO, the devastating neovascular glaucoma resulting from anterior segment neovascularization is seen only in ischemic CRVO. Fortunately, most cases $(81 \%)$ (Hayreh et al., 1994) are of the non-ischemic type that rarely develops blindnesscausing complications.

\subsection{Risk factors of RVO}

CRVO and BRVO have different symptoms, risk factors, pathogenesis, and therefore treatment. The pathogenesis for RVO is multifactorial and still under investigation. Anatomical positions of retinal veins play an important role in the pathogenesis of RVO (Fraenkl et al., 2010). The central retinal artery and vein share a common adventitial sheath in the optic nerve head. In CRVO, the tract of central retinal vein passing through the narrowing lamina cribrosa is the most frequent site of occlusion. In BRVO, vein occlusions occur at the junction of retinal vein and artery crossings in the retina. The mechanical compression of the veins at the narrowing passage or arteriovenous crossings predispose retinal veins to thrombus formation by various factors, including slowed or disturbed blood flow, endothelial damage in the vessel wall, changes in the blood viscosity, perivascular changes such as in lamina cribrosa (Albon et al., 1995), and sclerotic changes in the retinal arteries. Ocular risk factors associated with RVO include glaucoma or ocular hypertension. In glaucoma, increased intraocular pressure causes mechanical compression of retinal veins, which may induce RVO.

RVO has often been associated with a variety of systemic vascular disorders including arterial hypertension, arteriosclerosis, diabetes mellitus, dyslipidemia, and systemic vasculitis (The Eye Disease Case-Control Study Group, 1993, 1996; Koizumi et al., 2007; Mitchell et al., 1996; Sperduto et al., 1998). The increased rigidity of arterial wall affiliated with these diseases may result in compression of retinal veins.

Abnormal blood viscosity, platelets, and coagulation have also been suggested to be involved in RVO pathogenesis (Trope et al., 1983). Hematological dysfunction, such as increased plasma fibrinogen and disruption of the thrombosis-fibrinolysis balance, have been implicated in the development of RVO (Rehak and Rehak, 2008). Increased fibrinogen 
has been associated with RVO in several clinical reports (Lip et al., 1998; Patrassi et al., 1987; Peduzzi et al., 1986). An increasing number of studies have sought to establish an association between RVO and thrombophilic abnormalities. Thrombophilic risk factors related to RVO include hyperhomocysteinemia, methylenetetrahydrofolate reductase (MTHFR) gene mutation, factor V Leiden mutation, protein $\mathrm{C}$ and $\mathrm{S}$ deficiency, antithrombin deficiency, prothrombin gene mutation, anticardiolipin antibodies and lupus anticoagulant. High levels of circulating homocysteine may damage the vascular endothelium by releasing free radicals, creating a hypercoagulable environment (Angayarkanni et al., 2008). It appears that there is an association between RVO and hyperhomocysteinaemia and anti-phospholipid antibodies. However, for the other thrombophilic risk factors, there is a lack of consistency among the studies and the association with RVO is inconclusive (Fegan, 2002; Janssen et al., 2005; Rehak and Rehak, 2008). More recently, elevated levels of soluble endothelial protein C receptor (sEPCR) emerged an important candidate risk factor especially for CRVO (Gumus et al., 2006).

Significantly increased concentrations of growth factors, cytokines, and chemokines such as VEGF, interleukin (IL)-6, IL-8, interferon-inducible $10-\mathrm{kDa}$ protein (IP-10), monocytochemotactic protein-1 (MCP-1), and platelet-derived growth factor (PDGF)-AA were observed in vitreous or aqueous humor samples of patients with RVO (Funk et al., 2009; Noma et al., 2009; Yoshimura et al., 2009). Excessive production of VEGF and inflammatory cytokines can be induced by ischemic conditions. The levels of VEGF and inflammatory cytokines are correlated with severity of retinal ischemia and macular edema (Noma et al., 2006), as well as neovascularization. A close correlation between aqueous VEGF levels and iris neovascularization and vascular permeability in CRVO patients has been found (Boyd et al., 2002).

\subsection{Oxidative stress and RVO}

Retinal ischemia that occurs in some cases of RVO could lead to the generation of ROS, and compromise the integrity of the BRB. In fact, RVO is a common complication of diabetic retinopathy, in which hypoxia-ischemia is thought to play a role in its pathogenesis. Many of the risk factors for RVO described above, such as alterations in blood flow, systemic vascular disorders, hypercoagulability, and elevated levels of pro-inflammatory cytokines, may also be associated with a state of oxidative stress (Simoncini et al., 2005). Indeed, in a case-control prospective study in young adult CRVO patients, serum levels of paraoxonase1 arylesterase (PON1-ARE) activity, reported to have antioxidant potential, were found to be negatively correlated with hyperhomocysteinemia and lipid peroxidation, an indicator of oxidative stress (Angayarkanni et al., 2008). Decreased levels of PON1-ARE activity as well as increased levels of the lipid peroxidation marker were shown to be risk factors for CRVO. In another case study, an individual with glucose-6-phosphate dehydrogenase(G6PD) deficiency was exposed to an oxidative stressor, and later developed CRVO (Kotwal et al., 2009). G6PD deficiency is known to increase erythrocyte vulnerability to oxidative stress, which may precipitate hemolysis, increased erythrocyte aggregation and erythrocyteendothelium interaction, leading to thrombosis (Kotwal et al., 2009). Anti-phospholipid antibodies have been associated with the development of RVO, and shown to induce oxidative stress in endothelial cells (Simoncini et al., 2005). Taken together, these lines of evidence suggest that a state of oxidative stress may predispose individuals to RVO. 


\subsection{Therapeutics associated with the clinical presentation of RVO}

In addition to RVO that arises due to pathophysiological causes described above, this ocular disorder can also develop as an adverse event from treatment with certain therapeutics.

\subsubsection{Interferon- $\alpha$}

Interferon- $\alpha$ (IFN-a) is used for the treatment of many cancers and chronic hepatitis C. Interferon-associated retinopathy has been documented since the 1990s, most commonly characterized by hemorrhage and cotton-wool spots, and sometimes by macular edema, retinal vascular occlusion, and retinal ischemia. The RVO could involve either the vein or artery, or both, and in most cases is reversible. The exact pathophysiological mechanism of interferon-induced retinopathy is unknown, although there are similarities with early stages of diabetic retinopathy (Bajaire et al., 2011; Esmaeli et al., 2001). Several risk factors have been suggested, including hypertension, hyperlipidemia, a hypercoagulable state, and diabetes (Nadir et al., 2000). In addition, IFN-a is known to cause the development of autoantibodies in $10 \%$ of the patients receiving treatment, and to exacerbate certain systemic autoimmune diseases. It is speculated that IFN-a therapy might cause deposition of immune complexes in retinal vasculature, with sequelae of retinal ischemia, hemorrhages and cotton wool spots.

\subsubsection{Tumor necrosis factor}

Tumor necrosis factor (TNF) is a proinflammatory cytokine that has been implicated in various diseases, including autoimmune diseases, diabetes, and cancer. In a phase II trial of recombinant TNF in patients with advanced colon cancer, TNF was administered by i.v. infusions twice daily for 5 consecutive days every other week for 8 weeks (Kemeny et al., 1990). Two out of 16 patients developed retinal vein thrombosis several weeks following completion of therapy. This finding is consistent with the known role of TNF in vascular leakage and blood-retinal barrier breakdown in diabetic retinopathy (Frey and Antonetti, 2011). In support of this, a patient with macular edema secondary to BRVO saw an improvement in visual acuity and cessation of macular edema during treatment with infliximab, a TNF- $\alpha$ antibody, administered for rheumatoid arthritis (Kachi et al., 2010). Paradoxically, infliximab therapy has also been linked in several case studies to the development of retinal vein thrombosis/occlusion in a patient being treated for ulcerative colitis (Veerappan et al., 2008), psoriasis (Vergou et al., 2010), or Crohn's disease (Puli and Benage, 2003). The temporal relationship between infliximab infusion and retinopathy suggested the two may be causally related. In two of the three cases, a medical history of myocardial infarction or hyperlipidemia was noted, both of which considered risk factors for RVO. Moreover, all three of these diseases are inflammatory in nature, and may predispose patients to weakened BRB.

\subsubsection{MEK inhibitor PD0325901}

PD0325901 is a potent and selective MEK inhibitor, developed for the treatment of advanced cancer. MEK is a key molecule in the Ras-mitogen-activated protein kinase (MAPK) pathway, which has roles including cellular proliferation and survival, and its only known 
substrate is the extracellular signal-regulated kinase (ERK), which in turn phosphorylates and activates downstream molecules in the pathway (Fig. 2). In the phase I dose escalation clinical trial of PD0325901, dose-limiting RVO was observed, characterized by the presence of cotton wool spots, hemorrhages, and vein occlusion. RVO developed in 2 patients after 3.5-4 months of 10 or $15 \mathrm{mg}$ BID continuous treatment schedule, and in 1 patient after 9 months of $10 \mathrm{mg}$ BID on a 5 days on/ 2 days off schedule, and was reversible upon treatment discontinuation (LoRusso et al., 2010). It was noted that at doses $>=4 \mathrm{mg}$ BID, the systemic exposure of PD0325901 was equivalent to that in animal models that resulted in 90\% phosphorylated ERK (pERK) suppression (LoRusso et al., 2010). Therefore, the ocular lesions could be related to the prolonged and/or significant levels of pERK suppression.

Two other MEK inhibitors, CI-1040 and selumetinib (AZD6244), also progressed to the clinic, but did not cause RVO. CI-1040 is a structural analogue of PD0325901. Insufficient clinical efficacy was reported due to poor bioavailability and metabolic instability (Rinehart et al., 2004). Selumetinib caused blurred vision in $12 \%$ of patients at $>=100 \mathrm{mg}$ BID in a Phase I trial (Adjei et al., 2008); this finding was not reported in subsequent Phase II trials at the 100 mg BID dose (Bekaii-Saab et al., 2011; Bodoky et al., 2011). Compared to PD0325901, selumetinib is approximately 10 -fold less potent, and has a relatively poor bioavailability. Taken together, even though it is at present unclear whether PD0325901 caused RVO due to its deep inhibition of $\mathrm{pERK}$, or to its chemotype, the above evidence suggests that the incidence of ocular lesions correlates with the efficacy of MEK inhibition.

\section{Molecular mechanisms of MEK inhibitor PD0325901-Induced RVO}

To develop an animal model of RVO to investigate mechanisms of toxicity, an in-life study was performed in rabbits, in which PD0325901 was administered by intravitreal injection at doses of 0.5 and $1 \mathrm{mg} /$ eye, with an observation period of 2 weeks (Huang et al., 2009). The high dose was extrapolated to be a potentially toxic dose, while the low dose was chosen as a subtoxic dose, based on in vitro cytotoxicity data (Huang et al., 2009). As early as 1 day after treatment, the high dose produced hemorrhages and vascular leakage with branch occlusion. These lesions progressed to retinal detachment, edema, abnormal kinetic blood flow, and retinal vessel occlusion after 7 days. At the low dose, retinal vascular leakage was observed without vascular occlusion. Therefore, the rabbit model provided evidence that PD0325901 at sufficient ocular concentrations could lead to similar retinal lesions seen in the clinic.

The retinal vascular toxicity was not observed in preclinical safety studies where PD0325901 was administered orally in rats and dogs for up to 13 weeks (Huang et al., 2009). The difference in the level of ocular toxicity between rabbits and rats/dogs could be attributed to ocular drug concentration differences arising from local vs. systemic routes of administration. Since molecular events could precede overt signs of tissue injury, an investigative study was conducted in which rats were dosed orally for 3 or 5 days at 45 $\mathrm{mg} / \mathrm{kg} /$ day, estimated to be at $70 \%$ maximal tolerated dose (Huang et al., 2009). No retinal toxicity was observed by ophthalmic examinations or fundus fluorescein angiography. Despite the absence of overt injury, global gene expression profiling on vehicle and PD0325901-treated retinas revealed several mechanisms relevant to the development of $\mathrm{RVO}$, including oxidative stress response, acute phase and inflammatory response, BRB 


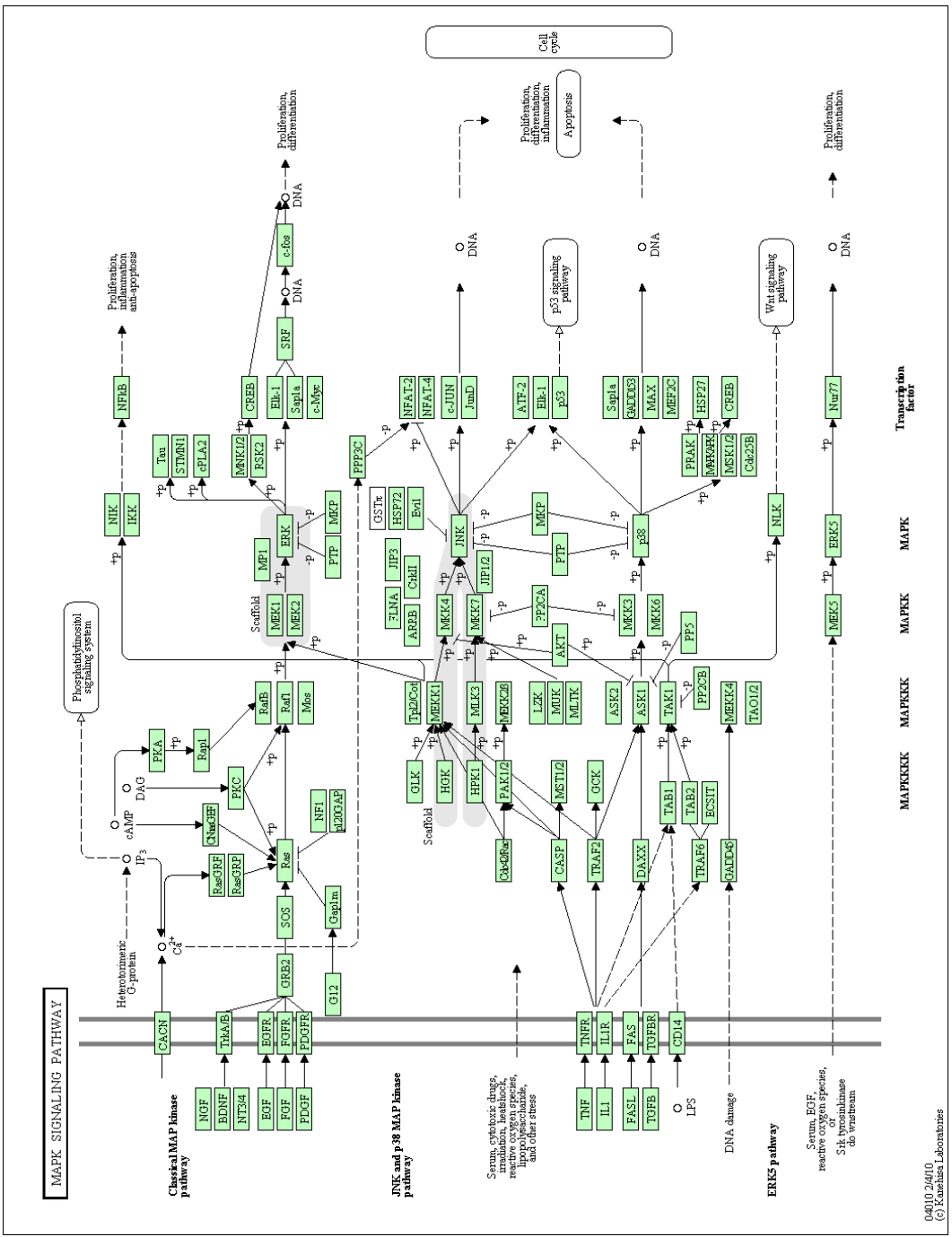

Fig. 2. MAPK signaling pathway The MAPK cascade is a highly conserved module that is involved in various cellular functions, including cell proliferation, differentiation and migration. Mammals express at least four distinctly regulated groups of MAPKs, ERK1/2, JNK1/2/3, p38alpha/beta/gamma/delta and ERK5, that are activated by specific MAPKKs: MEK1/2 for ERK1/2, MKK3/6 for the p38, MKK4/7 (JNKK1/2) for the JNKs, and MEK5 for ERK5. Each MAPKK, however, can be activated by more than one MAPKKK, increasing the complexity and diversity of MAPK signalling. Presumably each MAPKKK confers responsiveness to distinct stimuli. For example, activation of ERK1/2 by growth factors depends on the MAPKKK c-Raf, but other MAPKKKs may activate ERK1/2 in response to pro-inflammatory stimuli. Source: KEGG (http://www.genome.jp/dbgetbin/www_bget?map04010) (Kanehisa, 2000, 2012) 
breakdown, leukostasis, and activation of coagulation cascade (Huang et al., 2009). Progressive induction of oxidative stress response genes was observed over time, suggesting the tissue was mounting a response against ongoing oxidative stress. The induced genes encoding for antioxidant proteins include heat shock protein 27 (HSP27), $\alpha \beta$-crystalline, and those involved in glutathione synthesis/metabolism (GCLM, GSS, GSTs), and adhesion molecules; the only repressed genes were glutaredoxin 2 and peroxiredoxins. Of the oxidative stress response genes induced in this study, HSP27 and $\alpha \beta$-crystalline show some of the greatest magnitude of induction. These are small heat shock proteins that have diverse cytoprotective functions, including modulation of ubiquitin-proteosome pathway, inhibition of apoptosis, and increased resistance to oxidative stress and inflammation (Arrigo et al., 2007). Notably, the ubiquitin-proteosome pathway was significantly perturbed on both day 3 and day 5, which could be a response to misfolded proteins arising from oxidative stress. Antigen presentation by retinal cells is also a cited response to oxidative stress (Tezel et al., 2007; Zhang et al., 2005), consistent with the induction of $\beta$-2microglobulin gene of the major histocompatibility complex (MHC) class I on both day 3 and day 5. MHC class I molecules are normally expressed in the vascular endothelium and RPE (Zhang et al., 1997).

Multiple lines of evidence demonstrate that ROS mediate activation of the MAPK signaling pathway, which in turn modulates inflammation, intercellular junction assembly, actin cytoskeleton reorganization, and water transport, all of which are of critical importance to the maintenance of the BRB integrity. Disruption of one of the key MAPK pathways by PD0325901 could contribute to impaired BRB integrity, ultimately leading to retinal edema and RVO.

\subsection{MAPK activation and oxidative stress response in the retina}

Three main MAPK groups have been identified - ERKs, p38 MAPKs, and c-Jun N-terminal kinases (JNK). Typically, activation of ERKs are associated with growth-related signals, whereas p38 MAPKs and JNKs become activated in response to stress stimuli, including inflammation and oxidative stress (Fig. 2). However, the exact responses of these kinases in different cell types and tissue microenvironment under various experimental stimuli have proven to be more dynamic and less dichotomous than characterized above. Some degree of cross-talk also exist between these pathways (Houle and Huot, 2006). In the retina, the dynamic balance and cross-talk of these MAPK signaling pathways in cell types comprising the BRB, chiefly RPE, endothelial, and Müller cells, has been shown in experimental systems to be critical for modulating the integrity of the BRB.

The role of the MAPK pathway has been extensively investigated in cultured RPE cells (ARPE-19) following experimentally induced oxidative stress. In response to oxidants such as hydrogen peroxide or tert-butyl hydroperoxide, MAPK (most notably ERKs and p38 MAPK) activation has been shown to either protect against or exacerbate oxidative injury, differentiated by the amount of RPE cell death (Chan et al., 2008; Dong et al., 2011; Glotin et al., 2006; Jiang et al., 2009; Klettner and Roider, 2009; Qin et al., 2006; Tsao et al., 2006; Wang et al., 1998; $\mathrm{Wu}$ et al., 2010). These findings also raise questions as to the impact of oxidative stress on the outer BRB when the MAPK pathway is modulated pharmacologically by a MEK inhibitor. In endothelial cells, ROS are known to modulate the expression of redoxsensitive signaling pathways, including the MAPK cascades (Kunsch and Medford, 1999; 
Ushio-Fukai and Alexander, 2004), and inhibition of the ERK1/2 has been shown to lead to endothelial apoptosis (Huot et al., 1998). In a porcine model of retinal ischemia-reperfusion, Müller cells exhibited increased levels of glial fibrillary acidic protein (GFAP) and phosphorylated ERK proteins, implicating ERK in the process of glial activation in response to oxidative/ischemic stress (Wurm et al., 2011).

The following sections highlight specific MAPK-mediated molecular and cellular events in response to oxidative stress that are important for the maintenance of BRB function. The published data at times reveal contradictory findings with regards to whether the MAPKs are protective or disruptive in modulating these cellular processes following oxidative stress, underscoring the complexicity of these signaling pathways. In each section, literature review is followed by a discussion of relevant gene expression profiling data from the rat investigative study in which PD0325901 was administered orally for 3 or 5 days at 45 $\mathrm{mg} / \mathrm{kg} /$ day.

\subsubsection{MAPK activation and Inflammation in the retina}

Inflammation is a non-specific response to injury, and involves a plethora of cellular and molecular mediators. Chronic inflammatory processes are also an important source of ROS in the retina, and have been implicated in ocular diseases such as diabetic retinopathy and AMD. Both oxidative stress and inflammation negatively impact the integrity of the BRB. MAPKs mediate some of the downstream effects of proinflammatory cytokines such as IL-1, IL-6 and TNF- $\alpha$ (Du et al., 2010; Larrayoz et al., 2010; Wang et al., 2010).

In the 5-day rat investigative study involving PD0325901, hematology analysis revealed an increased number of phagocytes (neutrophils and monocytes) and increased plasma fibrinogen levels, indicating a mild inflammation in the compound treated animals. Consistently, the gene expression of many acute phase response proteins, such as lipocalin 2, fibronectin, fibrinogen, ferritin light chain, complement proteins, and coagulation factors, are significantly induced on day 5 . In addition to being an acute phase response protein, fibrinogen is also a key player in the coagulation cascade; as alluded in Section 4.2, it has been associated with the development of RVO in several clinical reports. Notably, some studies show that fibrinogen may increase endothelial permeability and mediate vasoconstriction through activation of ERK1/2 (Sen et al., 2009; Tyagi et al., 2008). Though the expression levels of IL-1, IL-6, IL-8, and TNF- $\alpha$ genes were not affected, induction of downstream genes within these signaling pathways, including TRAF6 (TNF receptor associated factor 6), TNF receptor, IкB kinase, signal transducer and activator of transcription (STAT) 3, c-Jun, collagen type I, intracellular adhesion molecule (ICAM-1), vascular cell adhesion molecule (VCAM)-1, and cyclooxygenase (Cox)-2, suggests pathway activation downstream of these cytokines. TNF- $\alpha$ has been shown to increase vascular permeability via modulation of tight junction proteins in diabetic retinopathy (Aveleira et al., 2010). IL-1 $\beta$ may have a role in mediating retinal capillary degradation in diabetic retinopathy (Frey and Antonetti, 2011). Intravitreal levels of IL-6 are correlated with macular edema in branch retinal vein occlusion (Noma et al., 2006). ICAM-1, VCAM-1 and Cox-2 are downstream effectors of NF-kB in the IL-8 signaling pathway. ICAM-1 and VCAM-1 are adhesions molecules expressed on vascular endothelial cells and their induction play a critical role in leukostasis and inflammation. Cox-2 mediates the production of 
proinflammatory prostaglandins. NF-kB, c-Jun and STAT3 are important regulators of many genes mediating mammalian inflammatory and immune responses. In addition, the expression of GFAP was induced on day 5, suggesting activation of Müller cells in response to retinal stress such as inflammation.

Conversely, glucocorticoids, which have anti-inflammatory properties, have been shown to have a positive impact on promoting barrier integrity. In a porcine model of RVO, triamcinolone treatment, a widely used glucocorticoid in ocular applications, reduced VEGF and increased tight junction occludin levels in the retina, suggesting increased BRB integrity (McAllister et al., 2009). A study conducted to examine the impact of Streptococcus suis infection on blood-CSF (cerebral spinal fluid) barrier showed that the glucocorticoid dexamethasone improved the barrier function by preventing tight junction protein reorganization and degradation, and attenuated ERK activation and matrix metalloproteinase 3 (MMP3) expression (Tenenbaum et al., 2008). Paradoxically, dexamethasone has also been shown to activate ERK and JNK, which in turn induce the expression of the anti-inflammatory mediator MAPK phosphatase 1 (MKP-1) in human umbilical vein endothelial cells (Furst et al., 2008). Activated MKP-1 is then able to terminate the activity of activated MAPKs in a negative feedback loop (Furst et al., 2008). These data further demonstrate the complex spatiotemporal signaling network in which the MAPKs participate.

In our gene expression analysis, the glucocorticoid receptor signaling pathway was one of the few pathways significantly perturbed on day 3 following PD0325901 administration at $45 \mathrm{mg} / \mathrm{kg} /$ day, and many genes within the pathway were induced. On day 5, many of the same pathway genes became repressed. This could indicate an adaptive response to ongoing inflammation in the retina. As alluded to earlier, HSP27 and $\alpha \beta$-crystallin levels were also induced following PD0325901 administration. Their gene products have the ability to interfere with inflammatory signaling, such as attenuation of TNF- $\alpha$, NF-kB signaling pathways, and may represent another cellular response to inflammation.

\subsubsection{MAPK-mediated modulation of intercellular junctions in response to oxidative stress}

Intercellular junctions are of critical importance to the integrity of the BRB function (Fig. 1). Oxidative stress is known to disrupt the structure and function of tight junctions and adherens junctions through MAPK activation, in both endothelial cells (Niwa et al., 2001; Simoncini et al., 2005; Usatyuk and Natarajan, 2004; Usatyuk et al., 2006; Yuan, 2002) and epithelial cells (Basuroy et al., 2006; Gonzalez et al., 2009), and these adverse effects on the junctional complexes could be ameliorated with the application of specific MAPK inhibitors. The presence of ROS could also induce the expression of the vascular permeability factor VEGF in endothelial cells (Chua et al., 1998; El-Remessy et al., 2003), often associated with downstream MAPK activation (Yang et al., 2010a; Zheng et al., 2010). In Müller cells, oxidative stress leads to decreased PEDF expression (Yoshida et al., 2009), thus relieving its antagonistic effect on VEGF action and subsequent MAPK activation in endothelial cells (Yafai et al., 2007), contributing to increased vascular permeability and breakdown of the inner BRB. 
In our 5-day rat investigative study, the expression of myosin light chain kinase (MLCK) was significantly increased as a result of NF-kB signaling. Phosphorylation of myosin light chain by MLCK leads to actin-mediated endothelial cell contraction and increases permeability of endothelial junctional barrier. Activation of phosphatidylinositol 3-kinase (PI3K), whose expression was induced on both day 3 and day 5, has also been shown to increase vascular permeability (Abid et al., 2004; Lee et al., 2006; Serban et al., 2008). In addition, induction of MMP14 was observed on day 5. Under inflammatory conditions, Müller cells are a source of matrix metalloproteinases which impair the barrier function of retinal endothelial cells by degradation of the tight junction protein occludin (Reichenbach et al., 2007). Taken together, these data suggest increased retinal endothelial cell permeability and impaired BRB function as a result of PD0325901 administration. On the other hand, our data set also uncovered induction of genes important for maintaining the vascular endothelial barrier function, presumably as feedback mechanism to counteract permeability increases, such as repression of RhoA and induction of Rac1 to facilitate reannealing of adherens junctions (Vandenbroucke et al., 2008); induction of tight junction components claudin 11 and JAM-2; and induction of PEDF, likely in Müller cells, which represses expression of VEGF and decreases vascular permeability (Reichenbach et al., 2007).

\subsubsection{Regulation of actin dynamics by MAPK in response to oxidative stress}

The remodeling of actin cytoskeleton is an important response in endothelial cells exposed to oxidative stress, and contributes to increased permeability of the endothelial barrier (Houle and Huot, 2006; Lum and Roebuck, 2001). Under physiological and pathological stress conditions, endothelial cells undergo cell shape change, intercellular gap formation, and remodeling of the actin cytoskeleton, characterized by stress fiber formation and reduced cortical actin band. The formation of stress fibers is dependent on actin polymerization, and increases the endothelial cells' capacity to resist stress. On the other hand, stress fibers also pull apart intercellular junctions, likely contributing to their disruption and impaired endothelial barrier integrity.

ROS-induced MAPK activation plays an important role in actin remodeling. ERKs, p38 and JNK have all been shown to regulate actin dynamics induced by oxidative stress in endothelial cells (El-Remessy et al., 2011; Houle and Huot, 2006; Houle et al., 2003; Huot et al., 1998; Schweitzer et al., 2011; Usatyuk and Natarajan, 2004). p38 MAPK activation leads to phosphorylation of HSP27, which promotes actin polymerization. ERK activation results in phosphorylation of tropomyosin-1, which contributes to focal adhesion assembly and stress fiber formation, and modulates cell contractility. Inhibition of ERK activity by the MEK inhibitor PD098059 led to misassembly of focal adhesions and membrane blebbing, ultimately resulting in apoptosis (Huot et al. 1998). Physio-pathological consequence of surface blebbing of endothelial cells includes narrowing of vascular lumen associated with increased vascular resistance. Bleb shedding may also contribute to obstruction of blood vessels. Consistent with this interplay of MAPKs and actin dynamics, treatment with PD0325901 in the 5-day rat investigative study led to induction of genes in actin cytoskeleton and focal adhesion signaling pathways on study day 5, supporting perturbation of actin dynamics, likely downstream of oxidative stress. These data also raise 
the possibility of membrane blebbing in retinal vasculature following PD0325901 treatment, contributing to the development of RVO.

\subsubsection{MAPK pathway and water permeability in response to oxidative stress}

Macular edema was observed in our animal model administered with PD0325901. Two factors contribute to the development of chronic edema in the retina: increased vascular permeability leading to excessive fluid buildup, and reduced fluid absorption from the retina back into the blood. Müller and RPE cells play an integral role in transcellular fluid equilibrium (Reichenbach et al., 2007). Aquaporin 4 (AQP4) expressed on Müller cells and AQP1 expressed on RPE cells facilitate bidirectional water movements to maintain the osmotic and hydrostatic equilibrium in the retina. The Müller cell-specific AQP4 is colocalized with the inwardly rectifying potassium channel Kir4.1. Together they mediate the co-transport of water and potassium ions from the retinal tissue into the blood under normal conditions. In various animal models of retinopathy, characterized by inflammatory or oxidative stress conditions, Kir4.1 channel becomes mislocalized, and its expression is decreased in some cases (Reichenbach et al., 2007). This may lead to an intracellular potassium overload, increased osmotic pressure, and consequently, Müller cell swelling. In a study employing a rat model of RVO, downregulation of AQP1, AQP4, and Kir4.1 were observed, in addition to an altered distribution of Kir4.1 protein. Consequently, Müller cells displayed a decrease in potassium currents and increased in size (Rehak et al., 2008).

Application triamcinolone, a glucocorticoid frequently used for diabetic macular edema due to its anti-inflammatory properties (Felinski and Antonetti, 2005), reduced Müller cell swelling in animal models of ischemia-reperfusion and diabetic retinopathy (Reichenbach et al., 2007). In a porcine model of RVO, triamcinolone treatment reduced the glial activation marker GFAP expression in Müller cells, and also increased BRB integrity, as evidenced by reduced VEGF and increased tight junction occludin levels, potentially contributing to the resolution of edema in the retina (McAllister et al., 2009).

MAPKs are known to play an important role in cellular osmotic stress regulation (Cowan and Storey, 2003; de Nadal et al., 2002). In RPE cells, ultraviolet radiation (UVB) and hydrogen peroxide treatment, both of which are oxidative stress inducers, resulted in AQP1 downregulation which was mediated by MEK/ERK activation (Jiang et al., 2009). In the brain, astrocyte swelling often accompanies vascular edema (Reichenbach et al., 2007). In astrocytes exposed to the oxidative stressor manganese or glial reactive injury, there was an altered expression of AQPs, mediated by the MEK/ERK and p38 MAPKs (McCoy and Sontheimer, 2010; Rao et al., 2010).

In our 5-day rat investigative study, the repression of the Müller cell-specific water channel AQP4 on both day 3 and day 5, coupled with the repression of the inwardly rectifying potassium channels (Kcnj5, Kcnj6), and sodium channels on day 5, signals impaired transcellular fluid transport. Given the evidence for inflammation, intercellular junction disruption and actin cytoskeleton changes in the retina following PD0325901 treatment, this fluid imbalance would contribute to the observed retinal edema in the study and further weaken BRB integrity. The documented involvement of MAPKs in regulating transcellular 
fluid balance in the retina and the brain raises the possibility that MEK inhibition may play a role in perturbing this equilibrium.

\subsection{MAPK, IFN- $\alpha$ and RVO}

Given the complex signaling cascades and cross-talk between various MAPK pathways in multiple cell types comprising the BRB, it is conceivable that inhibition of ERK activation by a MEK inhibitor could lead to dysregulated BRB integrity and subsequent development of RVO. Intriguingly, IFN-a treatment, which is also associated with the development of RVO in the clinic (see Section 4.4.1), has been shown to inhibit the activation of ERK and the associated survival effects, and that MEK and ERK inhibitors enhance the anti-proliferative effect of IFNa in tumor cells or transformed epithelial cells (Battcock et al., 2006; Caraglia et al., 2005; Caraglia et al., 2003; Christian et al., 2009; Li et al., 2004; Romerio et al., 2000; Romerio and Zella, 2002). Cross-talk between the IFN-a and Ras-MAPK pathways converge on the STAT family of transcription factors. STAT proteins are involved in cytokine, hormone, and growth factor signal transduction, mediating biological processes as diverse as cell proliferation, differentiation, apoptosis, transformation, inflammation and immune response (Caraglia et al., 2005). Activated Ras/MEK has been shown to inhibit the antiviral response of IFN-a by reducing STAT2 levels (Christian et al., 2009). It is conceivable that clinical IFN- $\alpha$ usage may perturb the balance of MAPK signaling pathways in the retina, disrupt BRB function, and ultimately contribute to the development of RVO. That both IFN-a therapy and PD0325901 inhibit ERK activation and are linked to clinical development of RVO lends further support to the hypothesis that modulation of the Ras-MAPK pathway and subsequently BRB permeability changes play a role in the pathogenesis of this ocular adverse event.

\section{Conclusion}

The BRB, consisting of an endothelial and an epithelial barrier, serves to regulate the bidirectional passage of macromolecules through the retina. Oxidative stress can negatively impact the equilibrium across the BRB, leading to cellular disruption and ocular disorders. MAPK pathways involving ERK, p38 and JNK play a central role in the oxidative stress response of the $\mathrm{BRB}$, modulating inflammatory response, actin cytoskeletal dynamics, water transport, as well as inter-epithelial and inter-endothelial adhesion molecule expression and redistribution. Disruption of the ERK signaling pathway by the MEK inhibitor PD0325901 may disrupt the balance and cross-talk between interconnected signaling networks and produce unexpected cellular sequalae. PD0325901-induced RVO could arise as a consequence of disruption of these tightly regulated molecular processes vital for proper functioning of the BRB. The animal models employed in our study serves as an investigative or screening paradigm for pre-clinical compounds suspected of RVO-inducing potential. Finally, while a firm connection between MEK inhibition and the development of RVO has not been established, it would be prudent for clinicians to monitor patients on MEK inhibitor therapy for signs of ocular adverse events.

\section{Acknowledgements}

The authors would like to thank Patrick Lappin for critical reading of the manuscript, and Constance Benedict for preparation of Fig. 1. 


\section{References}

Abid, M.R., Guo, S., Minami, T., Spokes, K.C., Ueki, K., Skurk, C., Walsh, K., and Aird, W.C. (2004). Vascular endothelial growth factor activates PI3K/Akt/forkhead signaling in endothelial cells. Arterioscler Thromb Vasc Biol 24, 294-300.

Adjei, A.A., Cohen, R.B., Franklin, W., Morris, C., Wilson, D., Molina, J.R., Hanson, L.J., Gore, L., Chow, L., Leong, S., et al. (2008). Phase I pharmacokinetic and pharmacodynamic study of the oral, small-molecule mitogen-activated protein kinase kinase 1/2 inhibitor AZD6244 (ARRY-142886) in patients with advanced cancers. J Clin Oncol 26, 2139-2146.

Albon, J., Karwatowski, W.S., Avery, N., Easty, D.L., and Duance, V.C. (1995). Changes in the collagenous matrix of the aging human lamina cribrosa. Br J Ophthalmol 79, 368-375.

Angayarkanni, N., Barathi, S., Seethalakshmi, T., Punitham, R., Sivaramakrishna, R., Suganeswari, G., and Tarun, S. (2008). Serum PON1 arylesterase activity in relation to hyperhomocysteinaemia and oxidative stress in young adult central retinal venous occlusion patients. Eye (Lond) 22, 969-974.

Arrigo, A.P., Simon, S., Gibert, B., Kretz-Remy, C., Nivon, M., Czekalla, A., Guillet, D., Moulin, M., Diaz-Latoud, C., and Vicart, P. (2007). Hsp27 (HspB1) and alphaBcrystallin (HspB5) as therapeutic targets. FEBS Lett 581, 3665-3674.

Aveleira, C.A., Lin, C.M., Abcouwer, S.F., Ambrosio, A.F., and Antonetti, D.A. (2010). TNFalpha signals through PKCzeta/NF-kappaB to alter the tight junction complex and increase retinal endothelial cell permeability. Diabetes 59, 2872-2882.

Bajaire, B.J., Paipilla, D.F., Arrieta, C.E., and Oudovitchenko, E. (2011). Mixed vascular occlusion in a patient with interferon-associated retinopathy. Case Report Ophthalmol 2, 23-29.

Basuroy, S., Seth, A., Elias, B., Naren, A.P., and Rao, R. (2006). MAPK interacts with occludin and mediates EGF-induced prevention of tight junction disruption by hydrogen peroxide. Biochem J 393, 69-77.

Battcock, S.M., Collier, T.W., Zu, D., and Hirasawa, K. (2006). Negative regulation of the alpha interferon-induced antiviral response by the Ras/Raf/MEK pathway. J Virol 80, 4422-4430.

Bekaii-Saab, T., Phelps, M.A., Li, X., Saji, M., Goff, L., Kauh, J.S., O'Neil, B.H., Balsom, S., Balint, C., Liersemann, R., et al. (2011). Multi-institutional phase II study of selumetinib in patients with metastatic biliary cancers. J Clin Oncol 29, 2357-2363.

Bodoky, G., Timcheva, C., Spigel, D.R., La Stella, P.J., Ciuleanu, T.E., Pover, G., and Tebbutt, N.C. (2011). A phase II open-label randomized study to assess the efficacy and safety of selumetinib (AZD6244 [ARRY-142886]) versus capecitabine in patients with advanced or metastatic pancreatic cancer who have failed first-line gemcitabine therapy. Invest New Drugs.

Boyd, S.R., Zachary, I., Chakravarthy, U., Allen, G.J., Wisdom, G.B., Cree, I.A., Martin, J.F., and Hykin, P.G. (2002). Correlation of increased vascular endothelial growth factor with neovascularization and permeability in ischemic central vein occlusion. Arch Ophthalmol 120, 1644-1650.

Brafman, A., Mett, I., Shafir, M., Gottlieb, H., Damari, G., Gozlan-Kelner, S., VishnevskiaDai, V., Skaliter, R., Einat, P., Faerman, A., et al. (2004). Inhibition of oxygen- 
induced retinopathy in RTP801-deficient mice. Invest Ophthalmol Vis Sci 45, 37963805.

Burke, J.M. (2008). Epithelial phenotype and the RPE: is the answer blowing in the Wnt? Prog Retin Eye Res 27, 579-595.

Busik, J.V., Mohr, S., and Grant, M.B. (2008). Hyperglycemia-induced reactive oxygen species toxicity to endothelial cells is dependent on paracrine mediators. Diabetes 57, 1952-1965.

Caraglia, M., Marra, M., Pelaia, G., Maselli, R., Caputi, M., Marsico, S.A., and Abbruzzese, A. (2005). Alpha-interferon and its effects on signal transduction pathways. J Cell Physiol 202, 323-335.

Caraglia, M., Tagliaferri, P., Marra, M., Giuberti, G., Budillon, A., Gennaro, E.D., Pepe, S., Vitale, G., Improta, S., Tassone, P., et al. (2003). EGF activates an inducible survival response via the RAS-> Erk-1/2 pathway to counteract interferon-alpha-mediated apoptosis in epidermoid cancer cells. Cell Death Differ 10, 218-229.

Chan, C.M., Huang, J.H., Lin, H.H., Chiang, H.S., Chen, B.H., Hong, J.Y., and Hung, C.F. (2008). Protective effects of (-)-epigallocatechin gallate on UVA-induced damage in ARPE19 cells. Mol Vis 14, 2528-2534.

Cheung, N., Klein, R., Wang, J.J., Cotch, M.F., Islam, A.F., Klein, B.E., Cushman, M., and Wong, T.Y. (2008). Traditional and novel cardiovascular risk factors for retinal vein occlusion: the multiethnic study of atherosclerosis. Invest Ophthalmol Vis Sci 49, 4297-4302.

Chibber, R., Ben-Mahmud, B.M., Chibber, S., and Kohner, E.M. (2007). Leukocytes in diabetic retinopathy. Curr Diabetes Rev 3, 3-14.

Christian, S.L., Collier, T.W., Zu, D., Licursi, M., Hough, C.M., and Hirasawa, K. (2009). Activated Ras/MEK inhibits the antiviral response of alpha interferon by reducing STAT2 levels. J Virol 83, 6717-6726.

Chua, C.C., Hamdy, R.C., and Chua, B.H. (1998). Upregulation of vascular endothelial growth factor by $\mathrm{H} 2 \mathrm{O} 2$ in rat heart endothelial cells. Free Radic Biol Med 25, 891897.

Cowan, K.J., and Storey, K.B. (2003). Mitogen-activated protein kinases: new signaling pathways functioning in cellular responses to environmental stress. J Exp Biol 206, 1107-1115.

de Nadal, E., Alepuz, P.M., and Posas, F. (2002). Dealing with osmostress through MAP kinase activation. EMBO Rep 3, 735-740.

Dong, X., Li, Z., Wang, W., Zhang, W., Liu, S., and Zhang, X. (2011). Protective effect of canolol from oxidative stress-induced cell damage in ARPE-19 cells via an ERK mediated antioxidative pathway. Mol Vis 17, 2040-2048.

Du, Y., Tang, J., Li, G., Berti-Mattera, L., Lee, C.A., Bartkowski, D., Gale, D., Monahan, J., Niesman, M.R., Alton, G., et al. (2010). Effects of p38 MAPK inhibition on early stages of diabetic retinopathy and sensory nerve function. Invest Ophthalmol Vis Sci 51, 2158-2164.

El-Remessy, A.B., Behzadian, M.A., Abou-Mohamed, G., Franklin, T., Caldwell, R.W., and Caldwell, R.B. (2003). Experimental diabetes causes breakdown of the blood-retina barrier by a mechanism involving tyrosine nitration and increases in expression of vascular endothelial growth factor and urokinase plasminogen activator receptor. Am J Pathol 162, 1995-2004. 
El-Remessy, A.B., Rajesh, M., Mukhopadhyay, P., Horvath, B., Patel, V., Al-Gayyar, M.M., Pillai, B.A., and Pacher, P. (2011). Cannabinoid 1 receptor activation contributes to vascular inflammation and cell death in a mouse model of diabetic retinopathy and a human retinal cell line. Diabetologia 54, 1567-1578.

Esmaeli, B., Koller, C., Papadopoulos, N., and Romaguera, J. (2001). Interferon-induced retinopathy in asymptomatic cancer patients. Ophthalmology 108, 858-860.

Fegan, C.D. (2002). Central retinal vein occlusion and thrombophilia. Eye (Lond) 16, 98-106.

Felinski, E.A., and Antonetti, D.A. (2005). Glucocorticoid regulation of endothelial cell tight junction gene expression: novel treatments for diabetic retinopathy. Curr Eye Res 30, 949-957.

Fraenkl, S.A., Mozaffarieh, M., and Flammer, J. (2010). Retinal vein occlusions: The potential impact of a dysregulation of the retinal veins. EPMA J 1, 253-261.

Frey, T., and Antonetti, D.A. (2011). Alterations to the blood-retinal barrier in diabetes: cytokines and reactive oxygen species. Antioxid Redox Signal 15, 1271-1284.

Funk, M., Kriechbaum, K., Prager, F., Benesch, T., Georgopoulos, M., Zlabinger, G.J., and Schmidt-Erfurth, U. (2009). Intraocular concentrations of growth factors and cytokines in retinal vein occlusion and the effect of therapy with bevacizumab. Invest Ophthalmol Vis Sci 50, 1025-1032.

Furst, R., Zahler, S., and Vollmar, A.M. (2008). Dexamethasone-induced expression of endothelial mitogen-activated protein kinase phosphatase-1 involves activation of the transcription factors activator protein-1 and 3',5'-cyclic adenosine 5'monophosphate response element-binding protein and the generation of reactive oxygen species. Endocrinology 149, 3635-3642.

Garrido-Urbani, S., Bradfield, P.F., Lee, B.P., and Imhof, B.A. (2008). Vascular and epithelial junctions: a barrier for leucocyte migration. Biochem Soc Trans 36, 203-211.

Glotin, A.L., Calipel, A., Brossas, J.Y., Faussat, A.M., Treton, J., and Mascarelli, F. (2006). Sustained versus transient ERK1/2 signaling underlies the anti- and proapoptotic effects of oxidative stress in human RPE cells. Invest Ophthalmol Vis Sci 47, 46144623.

Gonzalez, J.E., DiGeronimo, R.J., Arthur, D.E., and King, J.M. (2009). Remodeling of the tight junction during recovery from exposure to hydrogen peroxide in kidney epithelial cells. Free Radic Biol Med 47, 1561-1569.

Gu, X., Samuel, S., El-Shabrawey, M., Caldwell, R.B., Bartoli, M., Marcus, D.M., and Brooks, S.E. (2002). Effects of sustained hyperoxia on revascularization in experimental retinopathy of prematurity. Invest Ophthalmol Vis Sci 43, 496-502.

Gumus, K., Kadayifcilar, S., Eldem, B., Saracbasi, O., Ozcebe, O., Dundar, S., and Kirazli, S. (2006). Is elevated level of soluble endothelial protein $C$ receptor a new risk factor for retinal vein occlusion? Clin Experiment Ophthalmol 34, 305-311.

Hardy, P., Beauchamp, M., Sennlaub, F., Gobeil, F., Jr., Tremblay, L., Mwaikambo, B., Lachapelle, P., and Chemtob, S. (2005). New insights into the retinal circulation: inflammatory lipid mediators in ischemic retinopathy. Prostaglandins Leukot Essent Fatty Acids 72, 301-325.

Hayreh, S.S., Zimmerman, M.B., and Podhajsky, P. (1994). Incidence of various types of retinal vein occlusion and their recurrence and demographic characteristics. Am J Ophthalmol 117, 429-441. 
Houle, F., and Huot, J. (2006). Dysregulation of the endothelial cellular response to oxidative stress in cancer. Mol Carcinog 45, 362-367.

Houle, F., Rousseau, S., Morrice, N., Luc, M., Mongrain, S., Turner, C.E., Tanaka, S., Moreau, P., and Huot, J. (2003). Extracellular signal-regulated kinase mediates phosphorylation of tropomyosin-1 to promote cytoskeleton remodeling in response to oxidative stress: impact on membrane blebbing. Mol Biol Cell 14, 1418-1432.

Huang, W., Yang, A.H., Matsumoto, D., Collette, W., Marroquin, L., Ko, M., Aguirre, S., and Younis, H.S. (2009). PD0325901, a mitogen-activated protein kinase kinase inhibitor, produces ocular toxicity in a rabbit animal model of retinal vein occlusion. J Ocul Pharmacol Ther 25, 519-530.

Huot, J., Houle, F., Rousseau, S., Deschesnes, R.G., Shah, G.M., and Landry, J. (1998). SAPK2/p38-dependent F-actin reorganization regulates early membrane blebbing during stress-induced apoptosis. J Cell Biol 143, 1361-1373.

Janssen, M.C., den Heijer, M., Cruysberg, J.R., Wollersheim, H., and Bredie, S.J. (2005). Retinal vein occlusion: a form of venous thrombosis or a complication of atherosclerosis? A meta-analysis of thrombophilic factors. Thromb Haemost 93, 1021-1026.

Jiang, Q., Cao, C., Lu, S., Kivlin, R., Wallin, B., Chu, W., Bi, Z., Wang, X., and Wan, Y. (2009). MEK/ERK pathway mediates UVB-induced AQP1 downregulation and water permeability impairment in human retinal pigment epithelial cells. Int J Mol Med 23, 771-777.

Kachi, S., Kobayashi, K., Ushida, H., Ito, Y., Kondo, M., and Terasaki, H. (2010). Regression of macular edema secondary to branch retinal vein occlusion during anti-TNFalpha therapy for rheumatoid arthritis. Clin Ophthalmol 4, 667-670.

Kanehisa, M. and Goto, S. (2000). KEGG: Kyoto Encyclopedia of Genes and Genomes. Nucleic Acids Res 28, 27-30.

Kanehisa, M., Goto, S., Sato, Y., Furumichi, M., and Tanabe, M. (2012). KEGG for integration and interpretation of large-scale molecular datasets. Nucleic Acids Res 40, D109D114.

Kaur, C., Foulds, W.S., and Ling, E.A. (2008). Blood-retinal barrier in hypoxic ischaemic conditions: basic concepts, clinical features and management. Prog Retin Eye Res 27, 622-647.

Kemeny, N., Childs, B., Larchian, W., Rosado, K., and Kelsen, D. (1990). A phase II trial of recombinant tumor necrosis factor in patients with advanced colorectal carcinoma. Cancer 66, 659-663.

Klein, R., Moss, S.E., Meuer, S.M., and Klein, B.E. (2008). The 15-year cumulative incidence of retinal vein occlusion: the Beaver Dam Eye Study. Arch Ophthalmol 126, 513518.

Klettner, A., and Roider, J. (2009). Constitutive and oxidative-stress-induced expression of VEGF in the RPE are differently regulated by different Mitogen-activated protein kinases. Graefes Arch Clin Exp Ophthalmol 247, 1487-1492.

Koizumi, H., Ferrara, D.C., Brue, C., and Spaide, R.F. (2007). Central retinal vein occlusion case-control study. Am J Ophthalmol 144, 858-863.

Kotwal, R.S., Butler, F.K., Jr., Murray, C.K., Hill, G.J., Rayfield, J.C., and Miles, E.A. (2009). Central retinal vein occlusion in an Army Ranger with glucose-6-phosphate dehydrogenase deficiency. J Spec Oper Med 9, 59-63. 
Kunsch, C., and Medford, R.M. (1999). Oxidative stress as a regulator of gene expression in the vasculature. Circ Res 85, 753-766.

Larrayoz, I.M., Huang, J.D., Lee, J.W., Pascual, I., and Rodriguez, I.R. (2010). 7ketocholesterol-induced inflammation: involvement of multiple kinase signaling pathways via NFkappaB but independently of reactive oxygen species formation. Invest Ophthalmol Vis Sci 51, 4942-4955.

Lee, K.S., Park, S.J., Kim, S.R., Min, K.H., Jin, S.M., Puri, K.D., and Lee, Y.C. (2006). Phosphoinositide 3-kinase-delta inhibitor reduces vascular permeability in a murine model of asthma. J Allergy Clin Immunol 118, 403-409.

Li, C., Chi, S., He, N., Zhang, X., Guicherit, O., Wagner, R., Tyring, S., and Xie, J. (2004). IFNalpha induces Fas expression and apoptosis in hedgehog pathway activated BCC cells through inhibiting Ras-Erk signaling. Oncogene 23, 1608-1617.

Lim, L.L., Cheung, N., Wang, J.J., Islam, F.M., Mitchell, P., Saw, S.M., Aung, T., and Wong, T.Y. (2008). Prevalence and risk factors of retinal vein occlusion in an Asian population. Br J Ophthalmol 92, 1316-1319.

Lip, P.L., Blann, A.D., Jones, A.F., and Lip, G.Y. (1998). Abnormalities in haemorheological factors and lipoprotein (a) in retinal vascular occlusion: implications for increased vascular risk. Eye 12 ( Pt 2), 245-251.

LoRusso, P.M., Krishnamurthi, S.S., Rinehart, J.J., Nabell, L.M., Malburg, L., Chapman, P.B., DePrimo, S.E., Bentivegna, S., Wilner, K.D., Tan, W., et al. (2010). Phase I pharmacokinetic and pharmacodynamic study of the oral MAPK/ERK kinase inhibitor PD-0325901 in patients with advanced cancers. Clin Cancer Res 16, 19241937.

Lum, H., and Roebuck, K.A. (2001). Oxidant stress and endothelial cell dysfunction. Am J Physiol Cell Physiol 280, C719-741.

Marcucci, R., Sofi, F., Grifoni, E., Sodi, A., and Prisco, D. (2011). Retinal vein occlusions: a review for the internist. Intern Emerg Med 6, 307-314.

McAllister, I.L., Vijayasekaran, S., Chen, S.D., and Yu, D.Y. (2009). Effect of triamcinolone acetonide on vascular endothelial growth factor and occludin levels in branch retinal vein occlusion. Am J Ophthalmol 147, 838-846, 846 e831-832.

McCoy, E., and Sontheimer, H. (2010). MAPK induces AQP1 expression in astrocytes following injury. Glia 58, 209-217.

Mitchell, P., Smith, W., and Chang, A. (1996). Prevalence and associations of retinal vein occlusion in Australia. The Blue Mountains Eye Study. Arch Ophthalmol 114, 12431247.

Nadir, A., Amin, A., Chalisa, N., and van Thiel, D.H. (2000). Retinal vein thrombosis associated with chronic hepatitis C: a case series and review of the literature. J Viral Hepat 7, 466-470.

Niessen, C.M. (2007) Tight junctions/adherens junctions: basic structure and function. J Invest Dermatol 127, 2525-32.

Niwa, K., Inanami, O., Ohta, T., Ito, S., Karino, T., and Kuwabara, M. (2001). p38 MAPK and $\mathrm{Ca} 2+$ contribute to hydrogen peroxide-induced increase of permeability in vascular endothelial cells but ERK does not. Free Radic Res 35, 519-527.

Noma, H., Funatsu, H., Mimura, T., Harino, S., and Hori, S. (2009). Vitreous levels of interleukin-6 and vascular endothelial growth factor in macular edema with central retinal vein occlusion. Ophthalmology 116, 87-93. 
Noma, H., Minamoto, A., Funatsu, H., Tsukamoto, H., Nakano, K., Yamashita, H., and Mishima, H.K. (2006). Intravitreal levels of vascular endothelial growth factor and interleukin-6 are correlated with macular edema in branch retinal vein occlusion. Graefes Arch Clin Exp Ophthalmol 244, 309-315.

Patrassi, G.M., Mares, M., Piermarocchi, S., Santarossa, A., Viero, M., and Girolami, A. (1987). Fibrinolytic behavior in long-standing branch retinal vein occlusion. Ophthalmic Res 19, 221-225.

Peduzzi, M., Debbia, A., Guerrieri, F., and Bolzani, R. (1986). Abnormal blood rheology in retinal vein occlusion. A preliminary report. Graefes Arch Clin Exp Ophthalmol 224, 83-85.

Puli, S.R., and Benage, D.D. (2003). Retinal vein thrombosis after infliximab (Remicade) treatment for Crohn's disease. Am J Gastroenterol 98, 939-940.

Qin, S., McLaughlin, A.P., and De Vries, G.W. (2006). Protection of RPE cells from oxidative injury by 15-deoxy-delta12,14-prostaglandin J2 by augmenting GSH and activating MAPK. Invest Ophthalmol Vis Sci 47, 5098-5105.

Rao, K.V., Jayakumar, A.R., Reddy, P.V., Tong, X., Curtis, K.M., and Norenberg, M.D. (2010). Aquaporin-4 in manganese-treated cultured astrocytes. Glia 58, 1490-1499.

Rehak, J., and Rehak, M. (2008). Branch retinal vein occlusion: pathogenesis, visual prognosis, and treatment modalities. Curr Eye Res 33, 111-131.

Rehak, M., Hollborn, M., Iandiev, I., Pannicke, T., Karl, A., Wurm, A., Kohen, L., Reichenbach, A., Wiedemann, P., and Bringmann, A. (2008). Retinal Gene Expression and Muller Cell Responses after Branch Retinal Vein Occlusion in the Rat. Invest Ophthalmol Vis Sci.

Reichenbach, A., Wurm, A., Pannicke, T., Iandiev, I., Wiedemann, P., and Bringmann, A. (2007). Muller cells as players in retinal degeneration and edema. Graefes Arch Clin Exp Ophthalmol 245, 627-636.

Rinehart, J., Adjei, A.A., Lorusso, P.M., Waterhouse, D., Hecht, J.R., Natale, R.B., Hamid, O., Varterasian, M., Asbury, P., Kaldjian, E.P., et al. (2004). Multicenter phase II study of the oral MEK inhibitor, CI-1040, in patients with advanced non-small-cell lung, breast, colon, and pancreatic cancer. J Clin Oncol 22, 4456-4462.

Rogers, S., McIntosh, R.L., Cheung, N., Lim, L., Wang, J.J., Mitchell, P., Kowalski, J.W., Nguyen, H., and Wong, T.Y. (2010). The prevalence of retinal vein occlusion: pooled data from population studies from the United States, Europe, Asia, and Australia. Ophthalmology 117, 313-319 e311.

Romerio, F., and Zella, D. (2002). MEK and ERK inhibitors enhance the anti-proliferative effect of interferon-alpha2b. Faseb J 16, 1680-1682.

Romerio, F., Riva, A., and Zella, D. (2000). Interferon-alpha2b reduces phosphorylation and activity of MEK and ERK through a Ras/Raf-independent mechanism. Br J Cancer 83, 532-538.

Schweitzer, K.S., Hatoum, H., Brown, M.B., Gupta, M., Justice, M.J., Beteck, B., Van Demark, M.J., Gu, Y., Presson, R.G., Jr., Hubbard, W.C., et al. (2011). Mechanisms of lung endothelial barrier disruption induced by cigarette smoke: role of oxidative stress and ceramides. Am J Physiol Lung Cell Mol Physiol.

Sen, U., Tyagi, N., Patibandla, P.K., Dean, W.L., Tyagi, S.C., Roberts, A.M., and Lominadze, D. (2009). Fibrinogen-induced endothelin-1 production from endothelial cells. Am J Physiol Cell Physiol 296, C840-847. 
Serban, D., Leng, J., and Cheresh, D. (2008). H-ras regulates angiogenesis and vascular permeability by activation of distinct downstream effectors. Circ Res 102, 13501358.

Simoncini, S., Sapet, C., Camoin-Jau, L., Bardin, N., Harle, J.R., Sampol, J., Dignat-George, F., and Anfosso, F. (2005). Role of reactive oxygen species and p38 MAPK in the induction of the pro-adhesive endothelial state mediated by IgG from patients with anti-phospholipid syndrome. Int Immunol 17, 489-500.

Siu, T.L., Morley, J.W., and Coroneo, M.T. (2008). Toxicology of the retina: advances in understanding the defence mechanisms and pathogenesis of drug- and lightinduced retinopathy. Clin Experiment Ophthalmol 36, 176-185.

Sperduto, R.D., Hiller, R., Chew, E., Seigel, D., Blair, N., Burton, T.C., Farber, M.D., Gragoudas, E.S., Haller, J., Seddon, J.M., et al. (1998). Risk factors for hemiretinal vein occlusion: comparison with risk factors for central and branch retinal vein occlusion: the eye disease case-control study. Ophthalmology 105, 765-771.

Sprague, A.H., and Khalil, R.A. (2009). Inflammatory cytokines in vascular dysfunction and vascular disease. Biochem Pharmacol 78, 539-552.

Tenenbaum, T., Matalon, D., Adam, R., Seibt, A., Wewer, C., Schwerk, C., Galla, H.J., and Schroten, H. (2008). Dexamethasone prevents alteration of tight junction-associated proteins and barrier function in porcine choroid plexus epithelial cells after infection with Streptococcus suis in vitro. Brain Res 1229, 1-17.

Tezel, G., Yang, X., Luo, C., Peng, Y., Sun, S.L., and Sun, D. (2007). Mechanisms of immune system activation in glaucoma: oxidative stress-stimulated antigen presentation by the retina and optic nerve head glia. Invest Ophthalmol Vis Sci 48, 705-714.

The Eye Disease Case-Control Study Group. (1993). Risk factors for branch retinal vein occlusion. Am J Ophthalmol 116, 286-296

The Eye Disease Case-Control Study Group. (1996). Risk factors for central retinal vein occlusion. Arch Ophthalmol 114, 545-554.

Trope, G.E., Lowe, G.D., McArdle, B.M., Douglas, J.T., Forbes, C.D., Prentice, C.M., and Foulds, W.S. (1983). Abnormal blood viscosity and haemostasis in long-standing retinal vein occlusion. Br J Ophthalmol 67, 137-142.

Tsao, Y.P., Ho, T.C., Chen, S.L., and Cheng, H.C. (2006). Pigment epithelium-derived factor inhibits oxidative stress-induced cell death by activation of extracellular signalregulated kinases in cultured retinal pigment epithelial cells. Life Sci 79, 545-550.

Tyagi, N., Roberts, A.M., Dean, W.L., Tyagi, S.C., and Lominadze, D. (2008). Fibrinogen induces endothelial cell permeability. Mol Cell Biochem 307, 13-22.

Uno, K., Prow, T.W., Bhutto, I.A., Yerrapureddy, A., McLeod, D.S., Yamamoto, M., Reddy, S.P., and Lutty, G.A. (2010). Role of Nrf2 in retinal vascular development and the vaso-obliterative phase of oxygen-induced retinopathy. Exp Eye Res 90, 493-500.

Usatyuk, P.V., and Natarajan, V. (2004). Role of mitogen-activated protein kinases in 4hydroxy-2-nonenal-induced actin remodeling and barrier function in endothelial cells. J Biol Chem 279, 11789-11797.

Usatyuk, P.V., Parinandi, N.L., and Natarajan, V. (2006). Redox regulation of 4-hydroxy-2nonenal-mediated endothelial barrier dysfunction by focal adhesion, adherens, and tight junction proteins. J Biol Chem 281, 35554-35566.

Ushio-Fukai, M., and Alexander, R.W. (2004). Reactive oxygen species as mediators of angiogenesis signaling: role of NAD(P)H oxidase. Mol Cell Biochem 264, 85-97. 
Vandenbroucke, E., Mehta, D., Minshall, R., and Malik, A.B. (2008). Regulation of endothelial junctional permeability. Ann N Y Acad Sci 1123, 134-145.

Veerappan, S.G., Kennedy, M., O'Morain, C.A., and Ryan, B.M. (2008). Retinal vein thrombosis following infliximab treatment for severe left-sided ulcerative colitis. Eur J Gastroenterol Hepatol 20, 588-589.

Vergou, T., Moustou, A.E., Maniateas, A., Stratigos, A.J., Katsambas, A., and Antoniou, C. (2010). Central retinal vein occlusion following infliximab treatment for plaquetype psoriasis. Int J Dermatol 49, 1215-1217.

Wang, X., Martindale, J.L., Liu, Y., and Holbrook, N.J. (1998). The cellular response to oxidative stress: influences of mitogen-activated protein kinase signalling pathways on cell survival. Biochem J 333 ( Pt 2), 291-300.

Wang, Y., Bian, Z.M., Yu, W.Z., Yan, Z., Chen, W.C., and Li, X.X. (2010). Induction of interleukin-8 gene expression and protein secretion by C-reactive protein in ARPE19 cells. Exp Eye Res 91, 135-142.

Wu, W.C., Hu, D.N., Gao, H.X., Chen, M., Wang, D., Rosen, R., and McCormick, S.A. (2010). Subtoxic levels hydrogen peroxide-induced production of interleukin-6 by retinal pigment epithelial cells. Mol Vis 16, 1864-1873.

Wurm, A., Iandiev, I., Uhlmann, S., Wiedemann, P., Reichenbach, A., Bringmann, A., and Pannicke, T. (2011). Effects of ischemia-reperfusion on physiological properties of Muller glial cells in the porcine retina. Invest Ophthalmol Vis Sci 52, 3360-3367.

Xu, L., Liu, W.W., Wang, Y.X., Yang, H., and Jonas, J.B. (2007). Retinal vein occlusions and mortality: the Beijing Eye Study. Am J Ophthalmol 144, 972-973.

Yafai, Y., Lange, J., Wiedemann, P., Reichenbach, A., and Eichler, W. (2007). Pigment epithelium-derived factor acts as an opponent of growth-stimulatory factors in retinal glial-endothelial cell interactions. Glia 55, 642-651.

Yang, J., Duh, E.J., Caldwell, R.B., and Behzadian, M.A. (2010a). Antipermeability function of PEDF involves blockade of the MAP kinase/GSK/beta-catenin signaling pathway and UPAR expression. Invest Ophthalmol Vis Sci 51, 3273-3280.

Yang, Y., Hayden, M.R., Sowers, S., Bagree, S.V., and Sowers, J.R. (2010b). Retinal redox stress and remodeling in cardiometabolic syndrome and diabetes. Oxid Med Cell Longev 3, 392-403.

Yoshida, Y., Yamagishi, S., Matsui, T., Jinnouchi, Y., Fukami, K., Imaizumi, T., and Yamakawa, R. (2009). Protective role of pigment epithelium-derived factor (PEDF) in early phase of experimental diabetic retinopathy. Diabetes Metab Res Rev 25, 678-686.

Yoshimura, T., Sonoda, K.H., Sugahara, M., Mochizuki, Y., Enaida, H., Oshima, Y., Ueno, A., Hata, Y., Yoshida, H., and Ishibashi, T. (2009). Comprehensive analysis of inflammatory immune mediators in vitreoretinal diseases. PLoS One 4, e8158.

Yuan, S.Y. (2002). Protein kinase signaling in the modulation of microvascular permeability. Vascul Pharmacol 39, 213-223.

Zhang, C., Lam, T.T., and Tso, M.O. (2005). Heterogeneous populations of microglia/macrophages in the retina and their activation after retinal ischemia and reperfusion injury. Exp Eye Res 81, 700-709.

Zhang, J., Wu, G.S., Ishimoto, S., Pararajasegaram, G., and Rao, N.A. (1997). Expression of major histocompatibility complex molecules in rodent retina. Immunohistochemical study. Invest Ophthalmol Vis Sci 38, 1848-1857. 
Zheng, Z., Chen, H., Wang, H., Ke, B., Zheng, B., Li, Q., Li, P., Su, L., Gu, Q., and Xu, X. (2010). Improvement of retinal vascular injury in diabetic rats by statins is associated with the inhibition of mitochondrial reactive oxygen species pathway mediated by peroxisome proliferator-activated receptor gamma coactivator 1alpha. Diabetes 59, 2315-2325. 


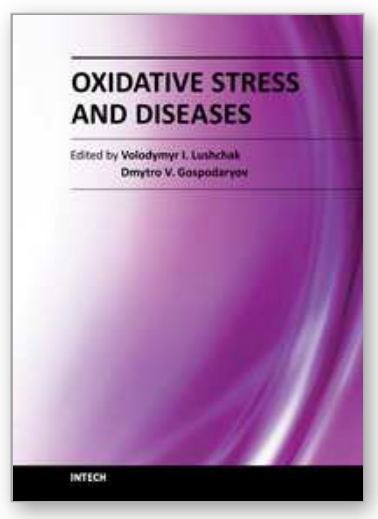

\author{
Oxidative Stress and Diseases \\ Edited by Dr. Volodymyr Lushchak
}

ISBN 978-953-51-0552-7

Hard cover, 610 pages

Publisher InTech

Published online 25, April, 2012

Published in print edition April, 2012

The development of hypothesis of oxidative stress in the 1980s stimulated the interest of biological and biomedical sciences that extends to this day. The contributions in this book provide the reader with the knowledge accumulated to date on the involvement of reactive oxygen species in different pathologies in humans and animals. The chapters are organized into sections based on specific groups of pathologies such as cardiovascular diseases, diabetes, cancer, neuronal, hormonal, and systemic ones. A special section highlights potential of antioxidants to protect organisms against deleterious effects of reactive species. This book should appeal to many researchers, who should find its information useful for advancing their fields.

\title{
How to reference
}

In order to correctly reference this scholarly work, feel free to copy and paste the following:

Amy H. Yang and Wenhu Huang (2012). Retinal Vein Occlusion Induced by a MEK Inhibitor - Impact of Oxidative Stress on the Blood-Retinal Barrier, Oxidative Stress and Diseases, Dr. Volodymyr Lushchak (Ed.), ISBN: 978-953-51-0552-7, InTech, Available from: http://www.intechopen.com/books/oxidative-stress-anddiseases/oxidative-stress-and-retinal-vein-occlusion

\section{INTECH}

open science | open minds

\section{InTech Europe}

University Campus STeP Ri Slavka Krautzeka 83/A 51000 Rijeka, Croatia Phone: +385 (51) 770447

Fax: +385 (51) 686166 www.intechopen.com

\section{InTech China}

Unit 405, Office Block, Hotel Equatorial Shanghai No.65, Yan An Road (West), Shanghai, 200040, China 中国上海市延安西路65号上海国际贵都大饭店办公楼405单元 Phone: +86-21-62489820

Fax: +86-21-62489821 
(C) 2012 The Author(s). Licensee IntechOpen. This is an open access article distributed under the terms of the Creative Commons Attribution 3.0 License, which permits unrestricted use, distribution, and reproduction in any medium, provided the original work is properly cited. 